\title{
A RARE VARIATION OF GREAT SAPHENOUS VEIN
}

Nakhate Manisha S1, Ghoshal Joy², Sawant V. G ${ }^{3}$

\section{HOW TO CITE THIS ARTICLE:}

Nakhate Manisha. S, Ghoshal Joy, Sawant V. G. "A Rare Variation of Great Saphenous Vein". Journal of Evolution of Medical and Dental Sciences 2014; Vol. 3, Issue 61, November 13; Page: 13625-13627,

DOI: $10.14260 /$ jemds/2014/3819

ABSTRACT: The venous system is more complex and variable than arterial system due to its frequent anatomical variations. This paper discusses the anatomy of the great saphenous vein and its variation observed in a male cadaver of around 60 years old.

KEYWORDS: Long Saphenous vein, Greater saphenous vein, Internal Saphenous vein.

INTRODUCTION: The Great saphenous vein (GSV) also known as long, internal or greater saphenous vein is the longest vein in our body. It originates from the anterior aspect of medical malleolus and runs along the tibial aspect of the medial calf before crossing the knee. The GSV then continues its course along the medial thigh before joining femoral vein at sapheno-femoral junction at the level of the groin skin crease.

At the ankle it receives tributaries from the sole of the foot. In the thigh it communicates with the femoral vein by perforator veins and receives numerous tributaries; those from the medial and posterior parts of the thigh frequently unite to form a large accessory saphenous vein which joins the main vein near the sapheno-femoral junction. The vein is often removed by vascular surgeons and used for auto transplantation in coronary artery bypass operations, when arterial grafts are not available or many grafts are required, such as in a triple bypass or quadruple bypass.

The great saphenous vein is the conduit of choice for vascular surgeons when available, for doing peripheral arterial bypass operations because it has superior long-term patency compared to synthetic grafts (PTFE, PETE (Dacron)), human umbilical vein grafts or biosynthetic grafts [Omniflow]. Often, it is used in situ (in place), after tying off smaller tributaries and stripping the valves.

CASE REPORT: During routine classroom cadaveric dissection in a 60 years old male we observed unilateral variation of great saphenous vein on the right side which was found to be duplication below knee, at level of medial condyle of Tibia. However, all the tributaries drained normally.

Before joining femoral vein, the two great saphenous veins joined together to form a single saphenous vein. Just before the level of saphenous opening.

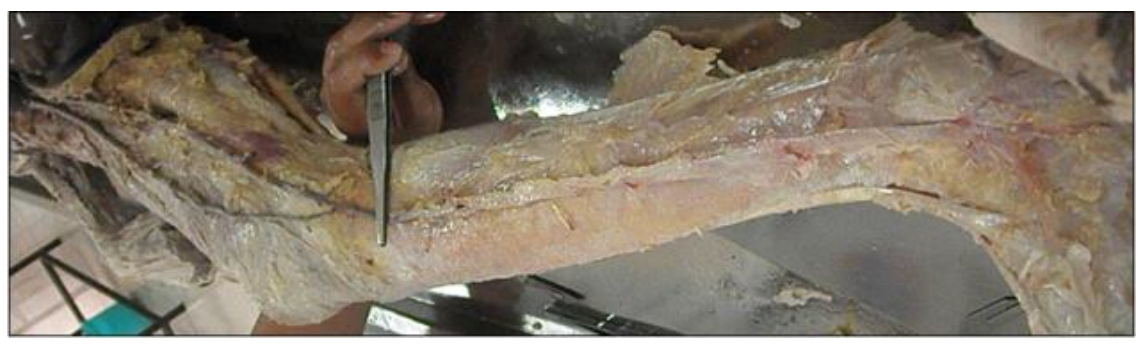

Fig. 1: Entire Course, Variant GSV 


\section{CASE REPORT}

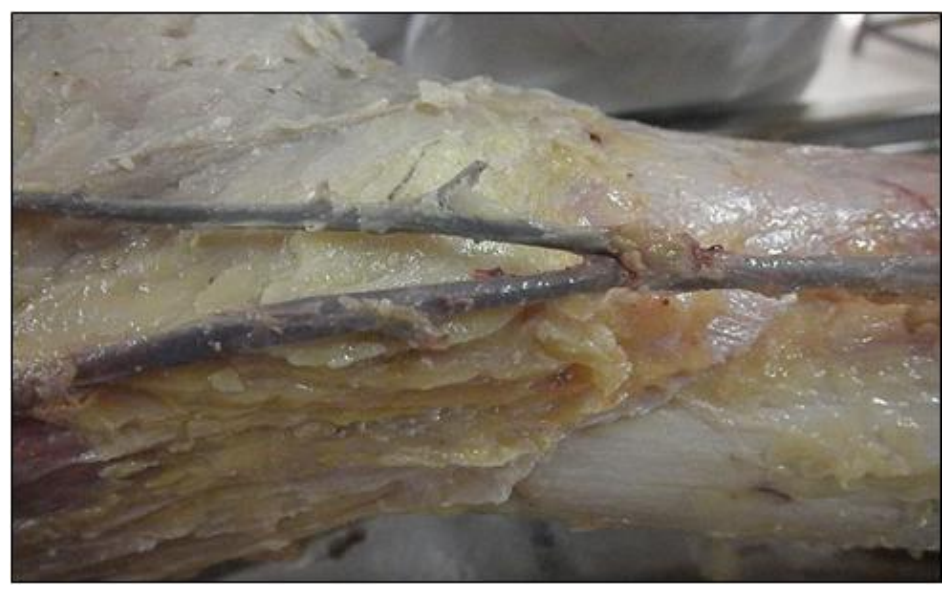

Fig. 2: Duplication below Knee

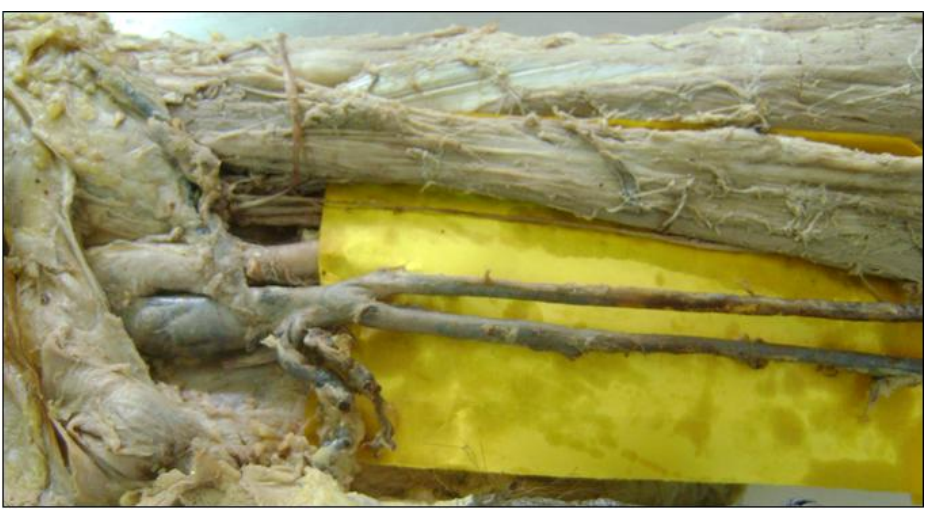

Fig. 3: Termination of Duplication of GSV

DISCUSSION: A rare anatomical variation found in this case that is duplication of GSV. Which has incidence of $1 \%$ ? Previously Daesler and his co-workers (1) found presence of lateral accessory saphenous vein.

Suzi-su-Hsin Chen and Shri kumar Prasad (2) have noted duplication of GSV in mid-thigh region.

A variable incidence of duplication of long saphenous vein has been reported both by duplex examinations and anatomical dissections. Glasser et al(3) observed an occurrence of duplication of great saphenous vein in $3 \%$ of dissected specimens while Ruoff et al(4) reported it in $18 \%$ of cases; Van Dijk et al(5) in $20 \%$ of the cases by duplex examination.

Corrales et al observed a high duplication rate of $49 \%$ by phlebography.(6) Donnelly et al,(7) through anatomical dissection found a duplication rate of $9 \%$.

Presence of duplication below knee level has not been noted till now. Both GSVs lie in the same cutaneous plane parallel to the skin and run along the aponeurotic deep fascia. These two GSVs also have same caliber draining a common cutaneous territory. An accessory saphenous vein is often mistaken as a duplication of GSV but accessory vein is usually smaller in size and does not drain the same cutaneous territory. 
APPLICATION: Though less commonly used in cardiac surgeries now-a-days, if duplication is found in the case can be used on additional graft source.

\section{REFERENCES:}

1. Hollinshed W H, Harper Ph.d \& Row, Publishers, Philadelphia. Episodes statistics 1991/2 London DHSc 1992 Anatomy for surgeons'.3rd ed. The Back and Limbs volume 3; 607-610.

2. Chen S H and Prasad S K. suzichen@med.monash.edu.au. Australian Journal of Ultrasound in Medicine. February 2009 12(4) 28.31.

3. Glasser ST. Variations of the tributaries of the saphena magna at the sapheno-femoral junction: abstract of demonstration. Anat Rec 1942; 82: 289-95.

4. Ruoff B A, Cranley J J, Hannan L A, Chang B B, et al. Real-time duplex ultrasound mapping of the greater saphenous vein before in situ infrainguinal revascularization. J Vasc Surg 1987; 8: 107-13.

5. Van Dijk L C, Wittens C H A, Pieterman H, van Urk H. The value of preoperative ultrasound mapping of the greater saphenous vein prior to close in situ bypass operations. Eur J of Radiol 1996; 23: 235-7.

6. Corrales NE, Irvine A, Mcguiness CL, Dourado $\mathrm{R}$, et al. Incidence and pattern of long saphenous vein duplication and its possible implications for recurrence after varicose vein surgery. Br J Surg 2002; 89: 323-6.

7. Donnelly M, Tierney S, Feeley M. Anatomical variation at the sapheno femoral junction. Br J Surg 2005; 92: 322-5.

\section{AUTHORS:}

1. Nakhate Manisha S.

2. Ghoshal Joy

3. Sawant V. G.

\section{PARTICULARS OF CONTRIBUTORS:}

1. Associate Professor, Department of Anatomy, Dr. D. Y. Patil School of Medicine, Nerul, Navi Mumbai.

2. Professor, Department of Anatomy, Dr. D. Y. Patil School of Medicine, Nerul, Navi Mumbai.

3. Professor and Head, Department of Anatomy, Dr. D. Y. Patil School of Medicine, Nerul, Navi Mumbai.

\section{NAME ADDRESS EMAIL ID OF THE} CORRESPONDING AUTHOR:

Dr. Nakhate Manisha S,

Flat No. 202, Yashwant Smriti,

Prashant Nagar, Behind Naupada Police Station, Naupada, Thane (West) - 400602,

Maharashtra.

Email:manishanakhate@yahoo.com

Date of Submission: 30/10/2014.

Date of Peer Review: 31/10/2014.

Date of Acceptance: 10/11/2014.

Date of Publishing: 13/11/2014. 